\title{
Análise das cooperativas de agricultores familiares atendidas pelo projeto de ATER "Mais Gestão" no estado do Paraná
}

\author{
Analysis of cooperatives of family farmers attended by the ATER project "More Management"
} in the state of Paraná

\section{Resumo}

A gestão de cooperativas é considerada complexa, haja vista os interesses diversos, bem como a tripla expectativa dos cooperados, pois são ao mesmo tempo clientes, donos e fornecedores. Este estudo teve por objetivo diagnosticar as práticas de gestão de 25 cooperativas da agricultura familiar do estado do Paraná, atendidas pelo projeto "Mais Gestão", do Ministério do Desenvolvimento Agrário-MDA. O estudo, de caráter documental, foi realizado tendo por base o pré-diagnóstico e a "Matriz de Identificação Estratégica" e mapeou o panorama da Gestão Organizacional; Gestão de Recursos Humanos; Finanças e Custos; Comercialização e Marketing; Gestão Industrial e Gestão Ambiental. Constatou-se que na Gestão Organizacional estão as maiores dificuldades, pois em 76\% das cooperativas a subárea estrutura organizacional possui desempenho "ruim". Conclui-se que as cooperativas da agricultura familiar estudadas precisam de maior apoio e incentivo na área de gestão organizacional, não se subtraindo, porém, a necessidade de apoio nas demais áreas.

Palavras-chave: Cooperativismo; Gestão de cooperativas; Diagnóstico

\begin{abstract}
The management of cooperatives is considered complex, considering the diverse interests as well as the tripled expectations of the cooperated, since they are at the same time customers, owners and suppliers. The objective of this study was to diagnose the management practices of 25 family farming cooperatives in the state of Paraná, Brazil, assisted by the "More Management" project of the Ministry of Agrarian Development (MDA). The documentary study was carried out based on the pre-diagnosis and the "Strategic Identification Matrix" and mapped the Organizational Management panorama; Human resource Management; Finance and Costs; Commercialization and Marketing; Industrial Management and Environmental Management. It was verified that the greatest difficulties reside in the Organizational Management, because $76 \%$ of the cooperatives the organizational structure sub-area has "bad" performance. In conclusion, the family farming cooperatives studied need greater support and encouragement in the area of organizational management but does not detract from the need of support in other areas.
\end{abstract}

Keywords: Cooperativism; Management of cooperatives; Diagnosis

Recebido: 25/11/2017 Aceito: 28/02/2018

Marcos Roberto Gregolin ${ }^{1}$, Graciela Caroline Gregolin², Valdecir José Zonin³ , Wilson João Zonin ${ }^{4}$

${ }^{1}$ Doutorando em Extensão Rural pela UFSM - marcosgregolin@yahoo.com.br

${ }^{2}$ Mestra em Desenvolvimento Rural Sustentável pela Universidade Estadual do Oeste do Paraná - gracigregolin@ hotmail.com

${ }^{3}$ Doutor em Agronegócios pela Universidade Federal do Rio Grande do Sul - UFRGS - valdecirzonin@ terra.com.br

${ }^{4}$ Doutorado em Meio Ambiente e Desenvolvimento Rural pela Universidade Federal do Paraná - wzonin@ yahoo.com.br 


\section{Introdução}

$\mathrm{O}$ termo Desenvolvimento, muito utilizado na atualidade, é, segundo Sachs (2008), consideravelmente complexo, sendo que tal complexidade se manifesta na gama de adjetivos que lhe foram atribuídos, sendo estes "econômico, social, político, cultural, sustentável” (SACHS, 2008, p. 37). Contudo, existe uma grande confusão nos discursos políticos, econômicos e acadêmicos, a qual é reflexo do falso entendimento enraizado na sociedade que trata, muitas vezes, o desenvolvimento como sinônimo de crescimento.

Desenvolver-se significa expandir ou realizar os potenciais de; trazer gradualmente a um estado mais completo, maior ou melhor. Quando algo cresce fica maior. Quando algo se desenvolve torna-se diferente (DALY, 2004, p. 198)

Tendo por 'base essas premissas, acredita-se que o Desenvolvimento, ao ser adjetivado como Sustentável não deve ter como produto a elevação do PIB (MARTINEZ-ALIER, 2008; SACHS, 2008), uma vez que "o objetivo maior se torna promover a igualdade e maximizar a vantagem daqueles que vivem nas piores condições, de forma a reduzir a pobreza, fenômeno vergonhoso, porquanto desnecessário, no nosso mundo de abundancia." (SACHS, 2008, p. 14).

Uma das alternativas apresentadas por diversos autores (SILVA; LOURENÇO; SALANEK FILHO, 2006; LOPES; MATOS; MACHADO, 2015; SCHNEIDER, 2015; LIMA FILHO, 2016) e por diversas organizações (ONU, FAO, OIT, ACI) para promover o Desenvolvimento com igualdade é o Cooperativismo, principalmente o cooperativismo conhecido como popular, de resistência ou solidário (ARROYO; SCHUCH, 2006). Uma organização que se baseia nos princípios de solidariedade é aquela que respeita e valoriza o ser humano e não o capital que ele dispõe. Neste tipo de segmento, o espaço em que as organizações estão inseridas também deve ser valorizado e respeitado. Ademais, de acordo com o entendimento de Lauschner (1994), Singer (2013) e Silva-Arioli et al (2016) afirma-se que uma organização verdadeiramente cooperativa é baseada, em primeira instância, em princípios de solidariedade.

A economia solidária também surge como uma ferramenta para que as pessoas possam ter liberdade.
O desenvolvimento preconizado por Sen (2013) é fundamentado na liberdade de escolha dos indivíduos e destoa de algumas prerrogativas relacionadas a outras concepções de desenvolvimento, como a elevação do PIB, aumento das riquezas pessoais, inovações tecnológicas não voltadas para o bem-estar da sociedade como um todo. "A visão de liberdade aqui adotada envolve tanto os processos que permitem a liberdade de ações e decisões como as oportunidades reais que as pessoas têm dada as suas circunstâncias pessoais e sociais." (SEN, 2013, p. 31).

Ademais, a liberdade atrelada à prática econômica solidária está non solum sed etiam relacionada à geração de renda para as famílias envolvidas nos empreendimentos, mas também na possibilidade de acesso aos mercados, que outrora lhe eram privados, garantidos e operados por grupos restritos da sociedade, ou seja, a liberdade não está somente na riqueza produzida por uma determinada operação comercial, mas sim na possibilidade de escolha que esse agente comerciante teve.

Salienta-se ainda, que a autogestão é o principal aspecto que diferencia as organizações calcadas na economia capitalista das fundamentadas nos princípios da economia solidária, cujas quais são desafiadas a "buscar um novo modelo de sociedade que supere o capitalismo, em termos de igualdade, liberdade e segurança para todos os cidadãos." (SINGER, 2013, p. 111).

Tendo por base o entendimento de Pires (2004), salienta-se que as primeiras experiências cooperativas no Brasil datam o século XIX, com o surgimento da Associação Cooperativa dos Empregados, em 1891, na cidade de Limeira-SP, e com a fundação da Cooperativa de Consumo de Camaragibe, em 1894, no estado de Pernambuco. Em 1902, surgem as primeiras experiências cooperativas Rurais no Rio Grande do Sul e, em 1907, as primeiras cooperativas agropecuárias no Estado de Minas (PIRES, 2004).

O principal ramo do cooperativismo brasileiro, já consagrado desde os anos 40 , foi o cooperativismo agrícola, que, conforme Pires (2004), não se consagra apenas em função da pujança de seus negócios, e sim por se constituir como um dos principais responsáveis "pela difusão do ideário cooperativista no país." (PIRES, 2004, p. 50). 
Ao se retomar a teorização de Singer, constatase a que a autogestão é uma condição de existência para os empreendimentos cooperativos, sejam eles da economia solidária, ou àqueles denominados por alguns autores como "cooperativas tradicionais" (DUARTE; WEHRMANN, 2006). Contudo, é uma prática que demanda um esforço considerável dos trabalhadores envolvidos no empreendimento, pois, "além de cumprir as tarefas a seu cargo, cada um deles tem de se preocupar com os problemas gerais da empresa." (SINGER, 2013, p. 19). Ademais, de acordo com as reflexões de Ignácio (2008), a gestão e o planejamento estratégico se apresentam como ferramentas para garantia de sobrevivência dos empreendimentos cooperativos nos mercados em que estão inseridos. Corrobora esta linha de raciocínio o entendimento de Schneider, (2012) ao afirmar que boa parcela dos fracassos no âmbito cooperativo se deve à "falta de visão empresarial, de conhecimento do mercado e de visão técnico administrativa" (Schneider, 2002, p. 252).

O Projeto "Mais Gestão" pode ser definido como uma ação de Assistência Técnica e Extensão Rural (ATER), respaldado pela Política Nacional de Assistência Técnica e Extensão Rural (PNATER), que surge como uma ferramenta para que as Cooperativas da Agricultura Familiar possam refletir e aprimorar os seus processos de gestão, conhecendo e enfrentando as dificuldades que influenciam negativamente o desempenho junto ao mercado, seja ele convencional ou institucional, privado ou solidário. Desse modo, tal projeto passa a existir como uma resposta às dificuldades encontradas pelas cooperativas da agricultura familiar no que concerne à gestão e aos problemas relacionados ao acesso do mercado.

De acordo com uma das chamadas públicas para contratação de entidade de prestação de serviço, o projeto se beneficia de uma metodologia pautada em abordagem multidisciplinar, a qual proporciona a identificação e posterior resolução de gargalos técnico-gerenciais e tecnológicos, cuja ação objetiva "incrementar a competitividade e promover a cultura de sustentabilidade social e econômica nos empreendimentos da agricultura familiar" (DATER, 2012, p. 25).

Têm-se como objetivos "específicos" deste projeto, em resumo, a promoção do associativismo e o desenvolvimento institucional dos empreendimentos da agricultura familiar; a ampliação do acesso destes empreendimentos aos produtos e serviços de apoio oriundos de instituições públicas e privadas; a introdução de melhorias técnico-gerenciais e tecnológicas; a incrementação do desempenho e contribuição para a elevação do emprego e renda; a realização de capacitação para inovação e a promoção do protagonismo dos empreendedores familiares no que diz respeito à articulação com as instituições de apoio e cooperação.

O "Mais Gestão" teve como desafio trabalhar tendo por base a especificidade de cada cooperativa atendida e como passos de sua execução cita-se: Mobilização e Seleção dos Empreendimentos; PréDiagnóstico Individual dos Empreendimentos; Diagnóstico dos Empreendimentos; Matriz de Identificação Estratégica (MIE) da metodologia de ATER Mais Gestão; Plano de Aprimoramento dos Empreendimentos; Visitas Técnicas para Implementação do Plano de Aprimoramento; Atualização do Plano de Aprimoramento e Encontro de Avaliação Final do Projeto (DATER, 2012).

Este artigo se justifica na medida em que conhecer o panorama da gestão destas cooperativas faz-se necessário e por constatar-se que a metodologia do projeto não proporcionou a confecção de um panorama geral do grupo de cooperativas atendidas. Nesse sentindo, constitui o objetivo deste estudo a caracterização das Cooperativas da Agricultura Familiar localizadas no estado do Paraná, de acordo com as práticas propostas pelo projeto de ATER "Mais Gestão", vinculado ao Ministério do Desenvolvimento Agrário (MDA).

\section{Metodologia}

\subsection{Cenário}

O cenário onde se desenvolveu esta pesquisa foi o Estado do Paraná, parte integrante do Lote $\mathrm{n}^{\circ} 08$ da chamada Pública $n^{\circ}$ 06/2012 (MDA), que visava a "seleção de entidade de Assistência Técnica e Extensão Rural para qualificação da gestão de empreendimentos coletivos da agricultura familiar visando seu fortalecimento e inserção nos mercados institucionais e privados". São beneficiárias dessa chamada pública 265 cooperativas da agricultura familiar, caracterizadas como pessoa jurídica e possuidoras de DAP Jurídica. Os lotes foram organizados tendo por base critérios de proximidade, acessibilidade, área e número de cooperativas. O lote 
$\mathrm{n}^{\circ}$ 08, que compreende os estados do Paraná e Santa Catarina, demandou o atendimento para 57 empreendimentos (25 no Paraná e 32 em Santa Catarina), teve como entidade selecionada a Agência de Desenvolvimento do Extremo Oeste do Paraná ADEOP, a qual executou a atividade entre abril de 2013 a janeiro de 2016.

\subsection{Sujeitos}

Os sujeitos desta pesquisa se distinguem como 25 Cooperativas da Agricultura Familiar com DAP Jurídica atendidas pela ADEOP no Projeto de Ater "Mais Gestão", localizadas no Estado do Paraná. Para as cooperativas da agricultura familiar do estado do Paraná se enquadrarem no atendimento do "Mais Gestão", foram realizadas audiências com instituições ligadas à agricultura familiar, tais como FETAEP, FETRAF, EMATER, INCRA, MDA, UNICAFES, onde foi elaborada uma lista de cooperativas, compreendendo as 25 prioritárias e alguma suplentes.

Tais cooperativas se caracterizam como: Cooperativas de produção de Leite (44\%), as quais compram a produção dos seus cooperados e/ou beneficiam, transformam ou vendem in natura para laticínios; Cooperativas de Comercialização (48\%), as quais cumprem um papel de organizar o processo de venda para mercados institucionais ou privados; e Cooperativas de Agroindustrialização (8\%), que compram matéria-prima de seus cooperados, transformam ou beneficiam os produtos e vendem ao mercado. Outra informação relevante sobre estas cooperativas é que no concerne a representação institucional, as poucas não filiadas a UNICAFES não dispunham de nenhum órgão de representação estadual ou federal.

Sobre o tempo de constituição das cooperativas tem-se que $48 \%$ delas possuem entre 8 a 10 anos, que $40 \%$ apresentam de 5 a 7 anos de existência, e que $12 \%$ se encontram na faixa de 2 a 4 anos. Ao se observar mais a fundo essas informações, constata-se que as cooperativas mais velhas são do ramo leite e que as outras mais novas iniciaram suas atividades em anos nos quais as políticas públicas de comercialização, sobretudo PAA e PNAE, começaram a ganhar força no cenário nacional.

A respeito do quadro social das cooperativas, em média composto por 146,16 cooperados, constatou-se variação de 20 a 800 integrantes. Ainda em se tratando do quadro social, nota-se que, em média, 117,96 cooperados são detentores de DAP Física, o que os torna reconhecidos como agricultores familiares pela SAF/MDA. Do total do quadro social das cooperativas, constatou-se que, em um extremo, existem apenas $27,40 \%$ dos cooperados ativos, em outro, $100 \%$ dos cooperados são atuantes no empreendimento, sendo a média dos cooperados atuantes de $85,01 \%$. Entende-se por cooperado atuante aquele que realiza operações comerciais com a cooperativa.

Sobre a postura comercial das cooperativas, constata-se que $32 \%$ delas atuam no mercado institucional (MI) e no mercado livre (ML) ao mesmo tempo, o que diversifica a sua fonte de renda, não ficando assim presas a nenhum dos segmentos. Exclusivamente no mercado livre, atuam $28 \%$ das cooperativas, sendo o mesmo percentual válido para as que atuam exclusivamente no mercado institucional. Sobre as cooperativas que atuam somente no mercado institucional, deduz-se que ou o fazem por estratégia, ou por não possuírem um mix de produtos suficientes para se manterem no mercado, ou ainda por não possuírem escala suficiente para atuar como fiel fornecedor de um único produto. $\mathrm{Da}$ totalidade das cooperativas, constatou-se que $12 \%$ não indicaram a realização de operações comerciais no ano de 2012.

Vale referenciar que o público beneficiário desta ação no estado do Paraná se caracteriza como cooperativas de agricultores familiares, e a partir disso salienta-se, de acordo com Costa, Junior e Silva (2015), que a gênese dessas organizações se deu como alternativa para que os agricultores familiares não ficassem a mercê das disputas de mercados, as quais foram acirradas pela globalização, ocasionando por vezes a sua exclusão do sistema de produção. Ainda de acordo com o entendimento destes autores, a constituição de uma cooperativa no âmbito da agricultura familiar "se mostra como uma importante ferramenta de organização social, política e econômica" (COSTA; JUNIOR; SILVA, 2015, p. 115). Ademais, para Batalha, Buainain e Filho (2005), o êxito da agricultura familiar no Brasil está fortemente relacionado à capacidade de gerar e agregar valor, e para este feito a criação de laços entre os agricultores, por meio de associações ou cooperativas, é muito importante.

Ao se estabelecer que as cooperativas, público alvo deste projeto, além de serem formadas 
por agricultores familiares e detentoras de DAP Jurídica, devem, prioritariamente ou preferencialmente possuir relações com o mercado, em específico com os programas de compras institucionais. Pode-se imaginar um divisor destas organizações com aquelas que ao longo do tempo se estabeleceram como cooperativas de pequenos agricultores, porém que se especializaram na recepção, classificação e comercialização de culturas, como trigo, soja e milho e também na comercialização de insumos agrícolas. Tais cooperativas, fundadas nos primórdios da colonização, sobretudo a Italiana e Alemã, principalmente no sul do país, se prestaram com eficiência a propagação e instalação do ideário da modernização agrícola e se estabeleceram como representantes hegemônicas do cooperativismo por um longo período de nossa história recente (FRANTZ, 2012).

Portador de um entendimento semelhante, Ávila et al. (2015) corroboram a contextualização do cooperativismo "forte no espaço rural brasileiro" e sua gênese relacionada com a chegada dos imigrantes europeus no final do século XIX e início do século $\mathrm{XX}$, contudo ele vai além ao afirmar que o movimento cooperativo de bases populares na agricultura familiar é mais recente, e tem sua origem principalmente vinculada ao "Movimento dos Sem Terra (MST) e outras organizações políticas ligadas a agricultura familiar somente a partir de 1989" (ÁVILA et al., 2015, p. 8).

O Cooperativismo como um todo, inclusive as organizações mencionadas anteriormente, por via de Lei é representado pela Organização das Cooperativas do Brasil (OCB), uma "sociedade civil, com sede na Capital Federal, órgão técnicoconsultivo do Governo, estruturada nos termos desta Lei, sem finalidade lucrativa" (BRASIL, 1971, artigo 105 , p. 17) a qual desde sua criação em 1969, durante o IV Congresso Brasileiro de Cooperativismo, em substituição a União Nacional das Associações Cooperativas (UNASCO) e a Aliança Brasileira de Cooperativas (ABCOOP), atuou de maneira hegemônica neste campo (MENDONÇA, 2011). Porém em meados de 1990 surgem discussões sobre a representatividade da $\mathrm{OCB}$, principalmente no que concerne às cooperativas menores, pouco atuantes em grandes mercados, guiadas ou condicionadas a atuação em mercados locais e em cadeias curtas, baseadas com mais ênfase em princípios de solidariedade do que em eficiência econômica, digase de passagem, valores estes que deveriam permear a racionalidade de todas as cooperativas, como afirma Lauschner (1994) "seja qual for o tipo de cooperativa, o cooperativismo é um modelo de economia solidária" (LAUSCHNER, 1994, p. 03).

\subsection{Recorte temporal}

Para a realização deste estudo utilizou-se dados secundários do projeto de Ater "Mais Gestão", levantados a campo pelos técnicos da ADEOP durante o ano de 2013 e 2014. A sistematização ocorreu em 2015. De acordo com Gerhardt e Silveira (2009), as pesquisas que utilizam dados secundários não exigem que o pesquisador se comprometa com a garantia da privacidade dos dados, contudo, tal premissa constituiu uma cláusula na autorização concedida para a pesquisa pelo Ministério do Desenvolvimento Agrário.

\subsection{Abordagem}

O presente estudo se valeu de uma abordagem qualitativa e quantitativa. A conciliação dessas duas técnicas é pertinente e corroborada pelo entendimento de Goode e Hatt (1972), quando afirmam que "a pesquisa moderna deve rejeitar como uma falsa dicotomia a separação entre estudos qualitativos e quantitativos, ou entre ponto de vista estatístico e não estatístico" (GOODE; HATT, 1972, p. 398).

Para responder aos objetivos que nortearam este estudo, foram analisadas duas ferramentas propostas pela Metodologia de Ater "Mais Gestão", cronologicamente empregadas a campo nessa sequência: pré-diagnóstico e matriz de identificação estratégica.

Por fim, pode-se classificar a presente pesquisa como documental, pois, de acordo com Gerhardt e Silveira (2009), tais pesquisas recorrem a fontes diversificadas como documentos internos e oficiais, relatórios de empresas e demais que não possuem tratamento analítico.

As informações utilizadas neste estudo foram sistematizadas por meio de software de planilha eletrônica, Microsoft Excel 2010. 


\subsection{Ferramentas}

Sobre o pré-diagnóstico, salienta-se que esta ferramenta foi utilizada no âmbito do projeto "Mais Gestão", tendo por objetivo angariar "informações que serão utilizadas para definir o perfil geral situacional da gestão dos empreendimentos antes da realização do diagnóstico" (DATER, 2012, p. 06). Trata-se de um formulário estruturado, em que as respostas podem ser abertas ou fechadas. Constatouse que o procedimento indicado para a coleta dessas informações foi o da conversa informal, apoiada pela observação direta, a qual tinha como objetivo angariar informações complementares em relação à entrevista. Segundo Lakatos e Marconi (2003), a observação direta é uma técnica que utiliza os sentidos, e não só o ver e ouvir. "A observação ajuda o pesquisador a identificar e obter provas a respeito de objetivos sobre os quais os indivíduos não têm consciência, mas que orientam seu comportamento" (LAKATOS; MARCONI, 2003, p. 191).

O pré-diagnóstico revelou temas relacionados à estrutura organizacional, características dos associados e da base produtiva, recursos humanos envolvidos no empreendimento, produtos e valores comercializados em tipos de mercados, estruturas de agroindustrialização, estruturas disponíveis para a logística, aspectos fiscais e tributários, acesso a políticas públicas, despesas, receitas e investimentos realizados nos últimos anos e vendas e marketing.

Sobre a "matriz de identificação estratégica", salienta-se que ela se caracteriza como uma representação gráfica da situação de gestão de cada cooperativa e é resultante da sistematização das informações angariadas no diagnóstico do empreendimento.

\section{Quadro 1 - Relação entre diagnóstico e Matriz de Identificação Estratégica.}

\begin{tabular}{|c|c|c|c|c|}
\hline A & B & $\mathrm{C}$ & D & $\mathrm{E}$ \\
\hline Resultado & Conceito & Questão & Subárea & Área \\
\hline \multirow{7}{*}{ 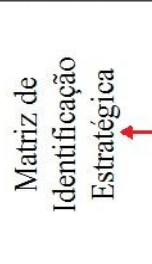 } & \multirow{7}{*}{ 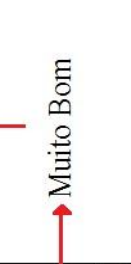 } & Questão 1-1 & \multirow{7}{*}{ 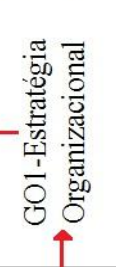 } & \multirow{7}{*}{ 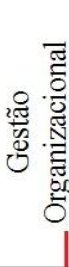 } \\
\hline & & Questão 2- & & \\
\hline & & Questão 3- & & \\
\hline & & Questão 4 & & \\
\hline & & Questão 5- & & \\
\hline & & Questão 6 - & & \\
\hline & & Questão 7- & & \\
\hline
\end{tabular}

Fonte: DATER (2012) e dados da pesquisa, organizado pelos autores.
Nesse sentido faz-se necessário um parênteses para contextualizar as características do diagnóstico, uma ferramenta organizada em 06 áreas (Coluna E) e 30 subáreas (Coluna D) e composto por 260 questões (Coluna C). Trata-se de um formulário com questões fechadas e também espaços para se anotar observações gerais, cujas respostas foram lançadas no sistema de geração de matriz de identificação estratégica - SGMIE. Esse sistema, desenvolvido especialmente para o "Mais Gestão", ponderou as respostas fornecidas para cada uma das questões (Sim, Não, Parcial e Não se aplica) e por meio desta ponderação atribuiu um conceito (Coluna B), que assumiu uma das momenclaturas "muito bom", "bom" ou "ruim", na matriz de identificação estratégica (Coluna A) a qual retrata a eficiência da cooperativa em todas as 30 subáreas analisadas nesse estudo.

\subsection{Natureza e objetivos}

Esta pesquisa também pode ser classificada como pesquisa aplicada, pois, segundo Gerhardt e Silveira (2009, p. 35), “objetiva gerar conhecimentos para aplicação prática, dirigidos à solução de problemas específicos. Envolve verdades e interesses locais". Quanto aos objetivos, a presente pesquisa pode ser classificada como descritiva, pois, de acordo com o entendimento de Gil (2008 p. 28), "as pesquisas deste tipo têm como objetivo primordial a descrição das características de determinada população ou fenômeno, ou o estabelecimento de relação entre as variáveis". Ainda de acordo com o entendimento do mesmo autor, este tipo de pesquisa é muito utilizado por "pesquisadores sociais preocupados com a atuação prática".

\section{Análise dos dados}

As cooperativas atendidas pelo projeto "Mais Gestão" constituem um grupo com vários pontos comuns, dentre eles, destaca-se o fato de possuírem DAP jurídica e a forte ou potencial relação com programas institucionais. Esses fatores, aliados à localização geográfica, basicamente em territórios ou regiões pobres, garantiram a escalação de cada uma delas para o "Mais Gestão". Contudo, elas se encontram em estágios diferenciados no que diz 
respeito à aplicação de rotinas de gestão. A seguir, destacam-se alguns aspectos relevantes que se apresentaram no universo desta pesquisa. Tais informações são provenientes da Matriz de Identificação Estratégica de cada cooperativa.

\subsection{Gestão organizacional}

Na área de Gestão Organizacional, constatouse que o desempenho "muito bom" apareceu em um baixo percentual das cooperativas, variando de 0 a $28 \%$ de acordo com a subárea em questão. Ainda como agravante, em duas dessas subáreas, revelou-se uma fragilidade ainda mais acentuada. Na subárea GO1 - Estratégia Organizacional, o atributo anteriormente abordado apareceu em apenas $20 \%$ dos sujeitos do estudo; já na subárea GO2 - Estrutura Organizacional, o desempenho "muito bom" não foi atribuído a nenhuma das 25 cooperativas. Do mesmo modo, essas duas subáreas são as que apresentaram a maior frequência de desempenho "ruim", respectivamente $44 \%$ e $76 \%$, conforme a Figura 1.

\section{Figura 1 - Sistematização dos conceitos atribuídos} na Área de Gestão Organizacional das cooperativas tendo por base o desempenho nas subáreas do

\section{Diagnóstico}

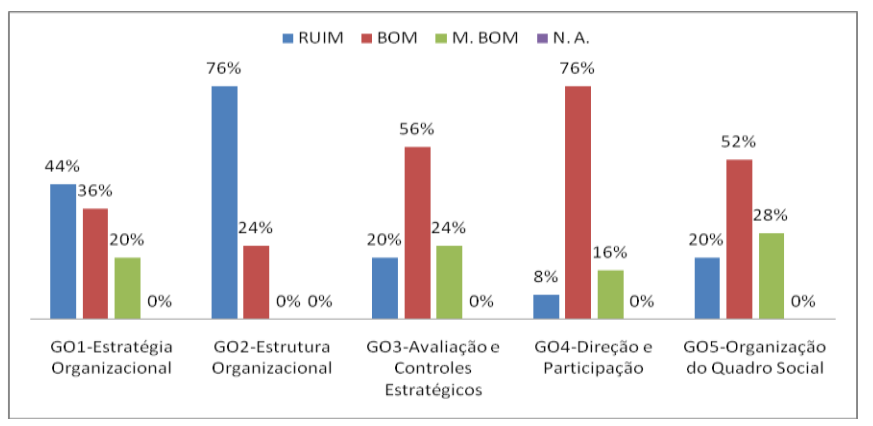

Fonte: Pesquisa (2015), organizado pelos autores.

Ao se analisar a questão proposta pela ferramenta do diagnóstico constata-se que a Estratégia Organizacional (G01) das cooperativas compreende a capacidade de refletir e planejar, tendo por base a observação do seu momento atual e o planejamento de situações futuras. Assim sendo, possuir missão, visão e valores definidos, bem como a assimilação desses por sua base cooperada, metas e objetivos econômicos definidos, além de realizar e monitorar planejamento estratégico, são aspectos levados em consideração para estabelecer a eficiência das cooperativas na subárea Gestão Organizacional. Segundo Dias (2002), o exercício dessas posturas administrativas pode tornar a gestão de uma organização mais eficiente.

A Estrutura Organizacional (GO2) foi avaliada tendo por base a existência de um organograma, se ele define autoridade e responsabilidades de maneira tangível, se existem procedimentos ou manuais com instruções operacionais e se há diferenças internas entre as áreas produtiva, comercial e gerencial. A grande incidência do atributo "ruim" e a não ocorrência do atributo "muito bom" oferecem indícios de que nessa subárea se encontram os maiores gargalos das cooperativas analisadas.

No que tange às subáreas (GO3, 4 e 5), constata-se uma incidência significativa de conceitos "bom" e "muito bom", e essa situação pode ser explicada pela relação tênue das minúcias dessas subáreas com alguns aspectos legais do cooperativismo, como, por exemplo, na subárea GO 3 - Avaliação e controles estratégicos, em que a atuação do conselho fiscal e a apresentação de relatórios contábeis e fiscais não constitui apenas uma ação condicionante de sucesso, mas sim uma prática exigida por lei. Ainda nessa mesma lógica, a realização de assembleia anual de prestação de contas está para a subárea GO4 assim como a atuação do conselho fiscal está para a subárea GO3. Em tempo, salienta-se que, no contexto geral da área Gestão Organizacional, há de se considerar o baixo desempenho das subáreas GO1 e GO2, as quais podem comprometer significativamente o desempenho do empreendimento. Tais subáreas possuem uma ligação com os princípios da economia solidária e do cooperativismo, principalmente com a autogestão. Planejamento, divisão de trabalho, metas, missão, visão, valores e especialmente a participação dos cooperados são premissas condicionantes da autogestão, cuja prática não constitui um exercício fácil, pelo contrário, demanda esforços e mudança de atitudes, sobretudo para aqueles que não foram "alfabetizados" em práticas desse teor (GUTIERREZ, 1998; SINGER, 2004; 2008; 2013).

\subsection{Gestão de pessoas}

Percebe-se que na área Gestão de Pessoas, bem como nas três subáreas que a compõem, o cenário não se apresenta como um grande limitante para as 
cooperativas. Na subárea Administração de Recursos Humanos (GP1) é onde se encontra a maior incidência de "bom" e a inexistência do atributo "ruim". A subárea diz respeito, especialmente, às relações de trabalho no empreendimento, legalidade dos contratos, rotinas de trabalho definidas, formação profissional dos gestores e se existe um plano de progressão na carreira. Nesse sentido, ao se observar o conteúdo da subárea e os números apresentados, nota-se que nela não se aglomeram reais limitantes para a gestão das cooperativas da agricultura familiar, haja vista a autonomia que as organizações possuem e a pouca dependência de funcionários. Contudo, um dos aspectos que pode gerar preocupação é a formação profissional dos gestores, pois, mesmo que esse papel seja exercido por um agricultor, é um aspecto muito importante a sua "profissionalização".

\section{Figura 2 - Sistematização dos conceitos atribuídos} na Área de Gestão de Pessoas das cooperativas tendo por base o desempenho nas subáreas do Diagnóstico

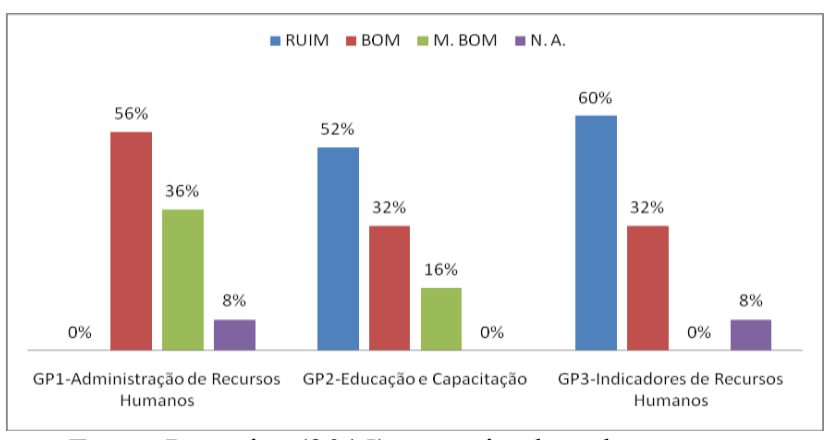

Fonte: Pesquisa (2015), organizado pelos autores.

Ainda tendo por base este raciocínio, na subárea Educação e Capacitação (GP2), composta por situações relativas à formação profissional dos empregados, monitoramento do aprendizado, incentivo para a capacitação, apoio aos funcionários que desejam se capacitar, verificou-se um desempenho menos favorável, pois, em $52 \%$ das cooperativas, constatou-se o desempenho "ruim" (Figura 2). Todavia, percebe-se que algumas das cooperativas preocupam-se com a formação e com a capacitação dos seus colaboradores, pois $32 \%$ apresentaram conceito "bom", e 16\%, "muito bom". $\mathrm{O}$ grande desafio nesse sentido pode consistir em pensar maneiras de potencializar essas ações formativas dos diretores, pois eles são comumente os administradores das cooperativas da agricultura familiar.

Já ná subárea Indicadores de Recursos Humanos (GP3), relacionada a práticas de controle e monitoramento das atividades dos funcionários, bem como sua satisfação em desempenhar o trabalho, o baixo desempenho, $60 \%$ das cooperativas com atributos "ruim", pode ser reflexo da pouca participação dos diretores na gestão do empreendimento, sobretudo no que se refere ao monitoramento da atuação dos colaboradores.

Ainda tendo por base o pré-diagnóstico, constatou-se que no âmbito das 25 cooperativas atendidas pelo projeto, existem 33 funcionários fixos e 9 temporários.

\section{Quadro 2 - Cooperativas e Número de Funcionários}

\begin{tabular}{|c|c|c|}
\hline Cooperativas com: & Fixo & Temporário \\
\hline Nenhum funcionário & 7 & 21 \\
\hline Apenas um funcionário & 11 & 1 \\
\hline Dois funcionários & 4 & 1 \\
\hline Três funcionários & 2 & 2 \\
\hline Quatro ou mais funcionários & 1 & 0 \\
\hline
\end{tabular}

Fonte: Pesquisa (2015), organizado pelos autores.

No caso das cooperativas que possuem funcionários, se ressalta a importância deste ativo no alcance dos objetivos organizacionais. Segundo Milkovich e Boudreau (2000), são as pessoas que dão vida às organizações, sem elas, qualquer planejamento pode se tornar inútil e as metas estabelecidas podem correr o risco de jamais serem alcançadas. Ainda de acordo com estes autores, as pessoas têm brilho e criatividade, "planejam e produzem os produtos e serviços, controlam a qualidade, vendem os produtos, alocam recursos financeiros e estabelecem as estratégias e objetivos para a organização" (MILKOVICH e BOUDREAU, 2000, p. 19). Em suma, as pessoas se encontram nas organizações, lado a lado com os demais recursos (financeiros e materiais) e a união destes ativos tende a favorecer as organizações na busca de seus objetivos (ORLICKAS, 1998).

A partir dessa constatação, deduz-se que o baixo número de funcionários contratados como efetivos nas cooperativas pode conferi-las diversos limites, principalmente no que tange às práticas de gestão e aos encaminhamentos diários necessários para o bom andamento do empreendimento. 
A perspectiva desses autores deixa clara a importância dos funcionários, estejam eles ligados a organizações convencionais ou da economia solidária. Contudo, é preciso considerar o fato de que todo e qualquer colaborador deve estar alinhado aos princípios da instituição, à sua missão, ao planejamento estratégico, à estrutura organizacional, gozando de seus direitos e respondendo aos seus deveres. Portanto, a gestão de recursos humanos precisa estar muito bem alinhada à gestão organizacional, conduzindo os funcionários para atender os objetivos estabelecidos da organização.

Sendo assim, pode-se inferir que, em uma perspectiva de importância para as cooperativas, encontra-se a gestão organizacional antes da gestão de pessoas, sem desonerar a segunda de sua responsabilidade. Porém, o universo de cooperados e de diretores dedicados à gestão é maior do que o universo de funcionários, além de que, para algumas cooperativas, exatamente em sete delas, não se constatou a presença de funcionários fixos.

\subsection{Finanças e custos}

Quanto a Finanças e Custos (Figura 3), constata-se que, no geral, as cooperativas apresentavam um desempenho "bom", exceto na subárea Indicadores de Custos (FC5), na qual o atributo "ruim" elevou-se consideravelmente e não houve incidência do atributo "muito bom". A subárea Administração Financeira (FC1) compreende a existência de um setor administrativo estruturado, com procedimentos e rotinas financeiras definidas, com um sistema ou programa de gestão que integre informações administrativas, financeiras e contábeis.

Figura 3 - Sistematização dos conceitos atribuidos na Área de Finanças e Custos das cooperativas tendo por base o desempenho nas subáreas do

\section{Diagnóstico}

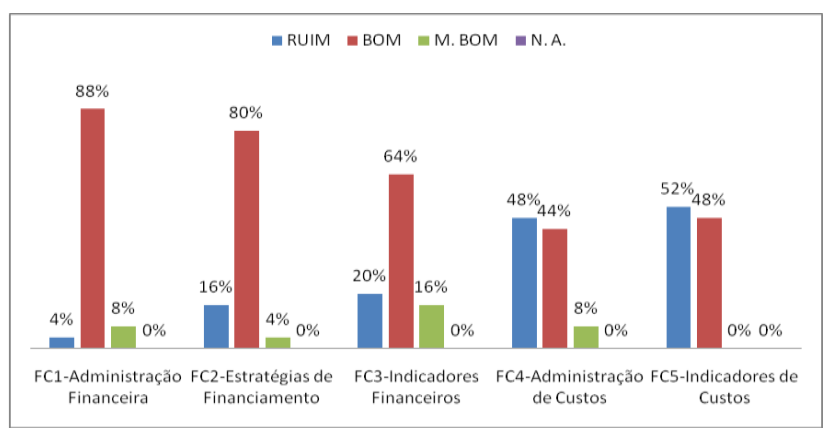

Fonte: Pesquisa (2015), organizada pelos autores.
De acordo com o diagnóstico, a eficiência nessa subárea também estava relacionada ao fato de estimar as receitas e planejar as despesas, controlar as contas a pagar e as contas a receber, bem como possuía-se uma situação favorável para a obtenção de crédito. Nessa subárea, o conjunto de cooperativas possuía $88 \%$ de desempenho "bom", e $8 \%$ de desempenho "muito bom", contrapondo com apenas 4\% de desempenho "ruim".

$\mathrm{O}$ acesso a políticas públicas de crédito $\mathrm{e}$ fomento, bem como o acesso a recursos não reembolsáveis e a prática de negociações de prazo com fornecedores e clientes para obter capital de giro compõem os pormenores da subárea Estratégias de Financiamento (FC2), na qual constatou-se que $80 \%$ das cooperativas possuíam desempenho "bom". Nesse caso, pode-se considerar como fatores motivadores, a facilidade no acesso às políticas públicas de financiamento, como PRONAF, PAA Formação de Estoque, microcrédito, Projetos de Infraestrutura e Serviços em Territórios Rurais (PROINF) e demais fontes não reembolsáveis.

A subárea Indicadores Financeiros (FC3), operacionalizada por meio da realização de fluxo de caixa, da análise do balanço financeiro, da percepção da necessidade de capital de giro e do cálculo de prazo médio para pagamento de fornecedores e recebimento de clientes, aparece como uma prática operada com eficiência ("muito bom") em apenas $16 \%$ das cooperativas. Ao passo que, em 64\% das cooperativas, esse desempenho foi regular ("bom"), e, em 20\%, o desempenho não foi suficiente ("ruim"). Tal situação pode ser influenciada pelo baixo número de funcionários atuantes nas cooperativas, pela baixa participação dos diretores na gestão dos empreendimentos, bem como a atuação deficitária dos conselhos fiscais, aos quais, dentre outras tarefas, cabe a análise mensal da situação financeira da cooperativa.

Sobre a atuação do conselho físcal na gestão financeira das cooperativas, cabe ressaltar que o mesmo não substitui a dedicação ou de um profissional contratado ou de um cooperado no dia a dia da gestão do empreendimento. Todavia, Bialoskorski Neto (2006) faz alusão à atuação do conselho fiscal e da responsabilidade que este órgão tem para com a manutenção da saúde financeira do empreendimento cooperativo, podendo contribuir 
muito para a autogestão das cooperativas. Entende-se que tal contribuição é intrínseca ao ideário cooperativista e uma manifestação da operacionalização dos princípios cooperativos, principalmente o da "Gestão Democrática", ideário e princípios que regem o universo cooperativista, sejam elas classificadas como de economia solidária ou tradicionais.

Posteriormente, nota-se uma inversão de desempenho, ou seja, nas subáreas anteriormente discutidas (FC1, 2 e 3 ), o percentual de cooperativas com o desempenho "bom" foi maior do que o percentual com desempenho "ruim", entretanto, nas subáreas seguintes (FC4 e 5), o desempenho "bom" recua, e o "ruim" eleva-se consideravelmente.

Para melhor compreensão, elucida-se que a adoção de práticas que diminuam os custos, o cálculo e a depreciação do patrimônio, bem como o registro de custos em uma ferramenta (digital ou material) são alguns dos itens que compõem a subárea Administração de Custos (FC4). Já a subárea Indicadores de Custos (FC5) faz menção ao cálculo da ociosidade dos empreendimentos, o giro do estoque, o volume de perda de matéria-prima e o ponto de equilíbrio da cooperativa.

Nota-se que, nas subáreas FC 1, 2 e 3, na maior parte das cooperativas, o desempenho foi "bom", e nas subáreas FC 4 e 5, o percentual de cooperativas em que o desempenho foi "ruim" elevou-se consideravelmente. A análise dos componentes de cada uma das subáreas pode auxiliar na compreensão deste fenômeno. Em uma análise superficial, parece claro que as práticas de gestão componentes das três primeiras subáreas estão mais próximas da realidade das cooperativas ou do pessoal que as opera, ao passo que as práticas das duas subáreas sequentes se apresentam como mais complexas, cuja operação demanda um maior preparo e capacidade do pessoal. A saber, as práticas componentes dessas subáreas são cálculo de depreciação do patrimônio, registro de custos, cálculo da ociosidade, o giro do estoque, o volume de perda de matéria-prima e o ponto de equilíbrio da cooperativa.

Nesse contexto, em se tratando de empreendimentos que atuam tendo por norte a economia solidária, que trabalham com a coleta e venda de leite (11 cooperativas) os que vendem produtos para os mercados institucionais (12 cooperativas), ou mesmo as cooperativas que compram matéria-prima e industrializam (2 cooperativas), nas quais as sobras são pequenas, fazse necessário um minucioso controle dos custos e de uma eficiente gestão financeira, visto que esses valores podem fazer a diferença no dia a dia da cooperativa e na distribuição de sobras aos cooperados no final do exercício.

\subsection{Comercialização e marketing}

Para a área Comercialização e Marketing, podese inferir que o desempenho das cooperativas, de modo geral, foi satisfatório, não obstante essa visão não dispensa a apuração de cada subárea. A primeira delas trata da Estrutura de Comercialização (CP1), ou seja, diagnostica a existência de vendas, da cooperação entre outras cooperativas, da existência de marca comercial e outros assuntos diretamente afetos a comercialização. Ao se observar a figura 4, percebe-se que, nessa subárea, $16 \%$ das cooperativas obtiveram um desempenho "muito bom" ao passo que para 52\% delas o desempenho foi "bom". Tais percentuais demonstram que, minimamente, as cooperativas apresentam preocupação com o planejamento das vendas e trabalham para aprimorar a atuação do mercado. Rapidamente, ao se observar no diagnóstico as perguntas da subárea Estrutura de Comercialização, constata-se que o que pode ter pesado negativamente é a pouca ou quase inexistente intercooperação e a não existência de um departamento ou setor comercial. Tais constatações, aliadas a outras, podem justificar o fato de que, em $32 \%$ das cooperativas, o desempenho da subárea foi "ruim".

$\mathrm{Na}$ sequência, contatou-se que a subárea Acesso aos Mercados Diferenciados e Institucionais (CP2) apresentou o melhor desemprenho dentro da grande área Comercialização e Marketing. Essa constatação corrobora-se no menor percentual de desempenho "ruim" (4\%) e o maior percentual de atributos "bom" (76\%) e "muito bom" (20\%), em comparação às demais subáreas. É um fato claro que estas cooperativas têm se dedicado com força expressiva ao atendimento do mercado institucional, mormente o PNAE e o PAA. Entretanto, o baixo desempenho "ruim" não deve ser considerado uma batalha vencida, podendo-se sugerir, como alternativas, a concentração de esforços e agendas propositivas para que essa atuação seja cada vez mais qualificada, o que garante a transposição da 
supremacia que, por muito tempo, foi imperada por atravessadores, os quais tinham a agricultura familiar como refém na comercialização (SIQUEIRA et al, 2013) ou por grupos comerciais que dominavam os mercados e não deixavam espaço para os produtos das cooperativas atenderem, sequer, às demandas locais.

\section{Figura 4 - Sistematização dos conceitos atribuidos na Área de Comercialização e Marketing das cooperativas tendo por base o desempenho nas subáreas do Diagnóstico}

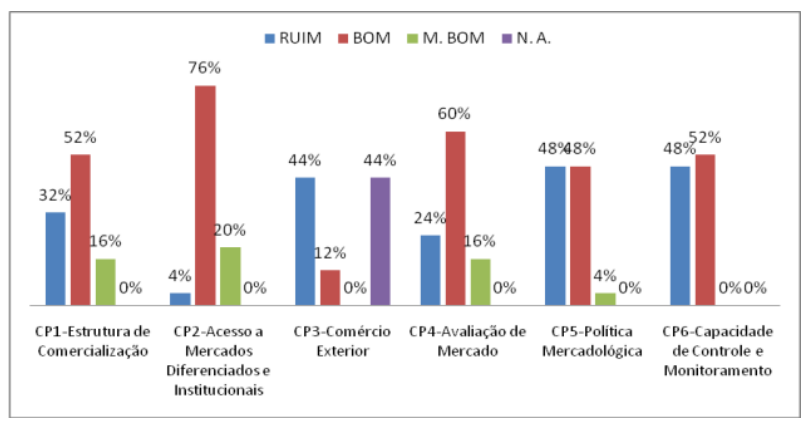

Fonte: Pesquisa (2015), organizado pelos autores.

No que concerne ao Comércio Exterior (CP3), o projeto "Mais Gestão" buscou compreender o nível de conhecimento das cooperativas sobre os procedimentos para exportação, se existia interesse por parte delas, além de saber se os empreendimentos já participaram de eventos ou feiras internacionais. No sentido de se conhecer os procedimentos e as vantagens de exportar, é que se apresenta o desempenho dessa subárea.

Assim sendo, em 44\% das cooperativas, o interesse no assunto não foi considerável ("ruim") e, em $12 \%$ das cooperativas, pode-se afirmar que existia uma determinada atração pelo tema ("bom"). Por outro lado, a sistematização do questionário realizada pelo SGMIE considerou que o comércio exterior não se aplica na realidade de $44 \%$ das cooperativas. A aparição do termo "não se aplica" se justifica pelo fato de que, nas questões componentes da subárea $\mathrm{CP} 3$, em um total de 08 , um grande número de "não se aplica" figurou no quadro de respostas das cooperativas.

Para a subárea Avaliação e Mercado (CP4), pode-se inferir que a total eficiência se encontrou em avaliar e acompanhar as tendências do mercado, além de conhecer a oscilação na demanda de produtos. De acordo com o "Mais Gestão", a utilização de pesquisas de mercado, o registo das sugestões dos clientes, o conhecimento dos concorrentes e dos preços por eles praticados e a identificação do tamanho da participação dos seus produtos no mercado, também são situações que condicionam o desempenho de um empreendimento cooperativo.

De acordo com Maximiano (2000), administrar a relação do empreendimento com o mercado é a principal função do administrador de marketing, ou daquele que se propõe a fazê-lo acontecer. Uma das ferramentas disponível para essa função é a aplicação dos $4 \mathrm{p}$ `s, e essa subárea faz concretas retomadas de tal ferramenta quando aborda temas como preço, pesquisa, relação com os clientes e outros. Ademais, em se tratando de um empreendimento cooperativo e solidário, espera-se que o seu marketing, ou seja, sua divulgação, primem sempre pelos valores éticos, com responsabilidade, principalmente nos produtos que vende, no relacionamento com os compradores e com os cooperados, seus fornecedores (CRÚZIO, 2003). Nesse aspecto, do total das cooperativas, $16 \%$ e $60 \%$ foram consideradas eficientes, pois conceituaram, respectivamente, "muito bom" e "bom". Para as demais (24\%), fora atribuído o conceito "ruim", tendo por base a constatação não satisfatória nas questões que compõem a subárea.

No tangente à subárea Política Mercadológica (CP5), têm-se princípios norteadores semelhantes aos da anterior, cabendo ressaltar os componentes divulgação, garantias e renovação do portifólio. Nesse estrato da área Comercialização e Marketing, os desempenhos "ruim" e "bom" apresentaram-se em $48 \%$ das cooperativas, e em $4 \%$ um desempenho "muito bom".

Por fim, para uma cooperativa que tem por objetivo crescer, a qual investe em produtos de qualidade, em redes para vendas e distribuição, marketing e propaganda, a Capacidade de Controle e Monitoramento (CP6) deve ser uma constante busca, pois é fator condicional para sua permanência, ou não, nos mercados. Entretanto, observou-se que uma grande parte das cooperativas estudadas não apresentaram um desempenho satisfatório, tendo em vista que $48 \%$ possuíam desempenho "ruim", 52\% foram considerados como "bom", e em nenhuma o conceito atribuído foi "muito bom". Nesse sentido, e para tornar os controles mais efetivos, dispor de estatísticas de vendas, monitorar o resultado financeiro, a margem de contribuição necessária para a sobrevivência da cooperativa e demais indicadores 
de desempenho, torna-se indispensável. As cooperativas da agricultura familiar contempladas nesse estudo, de acordo com a ferramenta de diagnóstico do "Mais Gestão" apresentaram, em um conjunto de $53 \%$ do total, um desempenho "bom" no que concerne ao controle e ao monitoramento, em oposição a $48 \%$ que revelaram um desempenho "ruim".

\subsection{Gestão industrial}

Dentre todas as áreas do diagnóstico, a Gestão Industrial foi a que esteve mais distante da realidade de maior parte das cooperativas, tendo em vista o alto percentual de "não se aplica" (Figura 5). Vale lembrar que uma subárea é enquadrada no item "não se aplica" quando a maior parte das questões que a compõem são informadas pelos entrevistados como não aplicáveis na realidade da cooperativa.

A subárea Produto (GI1) se refere a aspectos legais imperativos aos produtos industrializados como: ficha técnica, padrões de rotulagem, marca própria e outros. Sabendo-se que a maior parte das cooperativas entrega produtos in natura para $o$ mercado livre ou institucionais, pode-se inferir que essa realidade condicionou a atribuição do "não se aplica" em $24 \%$ das cooperaivas. Contudo, a utilização de um rótulo bem planejado e de marca comercial, mesmo esses não sendo uma exigência do mercado atendido, constitui um grande diferencial, o qual pode auxiliar na consolidação da cooperativa como fornecedora. As respostas fornecidas a essas práticas podem justificar a incidência do conceito "bom" em 56\% das cooperativas e "ruim" em $20 \%$ delas.

Figura 5 - Sistematização dos conceitos atribuídos na Área de Gestão Industrial das cooperativas tendo por base o desempenho nas subáreas do Diagnóstico

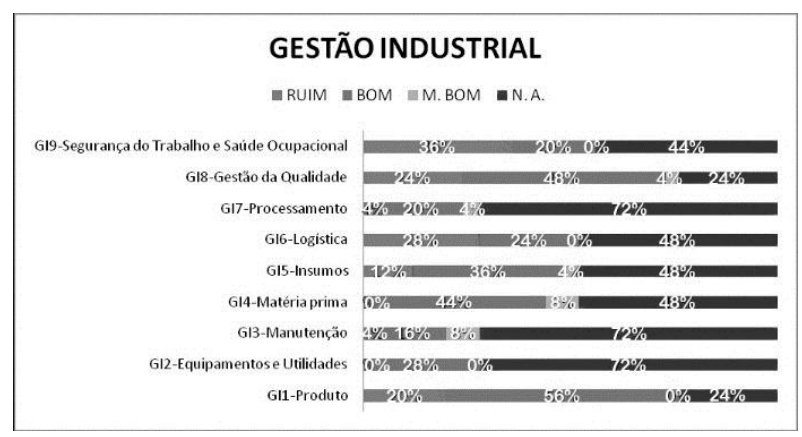

Fonte: Pesquisa (2015), organizado pelos autores.
A subárea Equipamentos e Utilidades (GI2), rotulada em um grande percentual de cooperativas como "não se aplica", faz referência aos utensílios utilizados no processo de agroindustrialização, o fácil acesso à manutenção, à utilização de seguro patrimonial para o maquinário e outros. Em $72 \%$ das cooperativas constatou-se a não aplicabilidade dos itens dessa subárea e, nas demais, constatou-se um bom grau de eficiência. Ademais, a subárea manutenção (GI3), salvo algumas peculiaridades, na qual se versa sobre os mesmos itens da anterior, constatou-se um idêntico percentual para a não aplicabilidade.

Em suma, equipamentos e manutenção constituem componentes importantes para as cooperativas da agricultura familiar, contudo - como mencionado anteriormente -, essas cooperativas nem sempre se dedicam ao beneficiamento e processamento de produtos e acabam por vender a matéria-prima para terceiros realizarem o processamento e transformação ou comercializam os produtos in natura para mercados institucionais. $\mathrm{O}$ não beneficiamento ou processamento dos produtos pode ser considerado um dos grandes gargalos do cooperativismo da agricultura familiar, principalmente em se tratando da agregação do valor e também do prazo de consumo dos alimentos, levando em conta que um produto agroindustrializado ou, pelo menos, minimamente processado, pode, além de ser mais valorizado, também ter uma vida útil maior do que o in natura.

Ponto central do processo agroindústrial, a Matéria-prima (GI4), é abordada no diagnóstico tendo por base o suprimento, a sazonalidade, o cadastro de fornecedores, a assistência técnica para a produção, o controle de qualidade, além de outros aspectos. Nesse sentido, a subárea GI4 ter se revelado com o desempenho "bom" em $48 \%$ das cooperativas, pode ser devido ao acesso de matéria-prima de qualidade, porém com práticas não regradas de seleção ou controle junto aos fornecedores, bem como o não fornecimento de assistência técnica aos cooperados produtores. Elencar tais possibilidades não constitui o objetivo desse estudo e, para aprofundar as minúcias de cada subárea, estudos específicos podem ser realizados.

O Acesso aos Insumos (GI5), bem como a gestão de estoque e o cadastro de fornecedores aparecem em $48 \%$ das cooperativas como não 
condizente à realidade (não se aplica), e a gestão dessa subárea é constada em 40\% (4\% "muito bom" e $36 \%$ "bom"). Em 12\% das cooperativas, a gestão dos insumos aparece como "ruim". Por mais que o item esteja bem relacionado com o processo de agroindustrialização, o controle de fornecedores, um mapa de produção dos cooperados ou um simples cadastro de produtores e produtos pode fazer a diferença no dia a dia das cooperativas, auxiliando no planejamento das vendas ou simplesmente na elaboração de projetos para o mercado institucional.

A subárea GI6, apesar se estar diretamente relacionado com a logística agroindustrial, armazenamento de matéria-prima, dimensões de estocagem, controle e monitoramento de estoque e armazenamento dos produtos finais, foi levada em consideração por alguns entrevistados, de maneira genérica. Desse modo, embora a maioria tenha declarado não aplicabilidade, em $28 \%$ das cooperativas, constatou-se o desempenho "ruim" e, em 24\%, o desempenho "bom". Um dos itens que pode ter sido levado em consideração pelas cooperativas, mesmo nos casos em que não existe agroindustrialização, é a estrutura de transporte, pois constitui uma realidade em casos nos quais a venda é apenas de produto in natura.

A subárea Processamento (GI7) aborda os aspectos inerentes à transformação de matériasprimas em produtos finais, ou seja, é um dos pilares da área gestão industrial. Ao observar as peculiaridades das cooperativas estudadas, percebese uma grande fragilidade do sistema, mais especificamente uma ruptura na cadeia produtiva, pois a agricultura familiar e suas cooperativas, em inúmeros casos, dedicam-se apenas à produção primária, repleta de custos $\mathrm{e}$ alheia ao real agregamento de valor. Os dados da Figura 5 corroboram essa afirmação, pois demonstram que, em $72 \%$ das cooperativas, o processamento não se aplica.

A subárea Gestão de Qualidade (GI8) se apresenta com um menor percentual de não aplicação (24\%), e tal fato pode ser esclarecido pelo entendimento dos gestores das cooperativas de que esse aspecto não é exclusivo das unidades agroindustriais, isto é, a qualidade precisa estar presente em qualquer produto alimentício comercializado. O "bom" e o "muito bom" desempenho nessa subárea foi constatado, respectivamente em $48 \%$ e $4 \%$ das cooperativas. Complementa esta análise a informação de que o desempenho "ruim" se revelou em $24 \%$ da população, constituindo assim um cenário que se revela como demandante de políticas públicas e ações de qualificação.

Por fim, a Segurança do Trabalho e Saúde Ocupacional (GI9) reúne aspectos legais que deveriam ser adotados por toda e qualquer instituição que apresenta funcionários envolvidos em processos de transformação ou manipulação de alimentos. Nas cooperativas tratadas neste estudo, a realidade não se apresenta muito favorável, pois, em 36\%, o desempenho é "ruim", e em $44 \%$ a realidade não se aplica, ficando em apenas $20 \%$ com um conceito "bom".

No geral, pode-se inferir que a área de "Gestão Industrial" precisa de melhores esclarecimentos quanto a sua aplicação em cooperativas agrícolas, especialmente em cooperativas da agricultura familiar, pois uma grande parcela delas não realiza processos de industrialização. Outrossim, tendo por base o entendimento de Zylbersztajn (2013) ao se tratar de agroindustrialização, não é pertinente desassociá-la do cultivo de produtos primários, sejam eles comercializados depois, ou antes, de algum beneficiamento. Esclarecer melhor o conceito de gestão industrial é algo necessário para as próximas aplicações do questionário do projeto "Mais Gestão" em futuras edições do projeto de ATER.

\subsection{Gestão ambiental}

A Gestão Ambiental, sexta área do diagnóstico o "Mais Gestão" é composta por apenas duas subáreas, Regularização Ambiental e Política Ambiental. Sobre a sustentabilidade ambiental, afirma-se que ela

[...] pode ser alcançada por meio da intensificação do uso dos recursos potenciais dos vários ecossistemas - com um mínimo de dano aos sistemas de sustentação da vida - para propósitos socialmente válidos; da limitação do consumo de combustíveis fósseis e de outros recursos e produtos facilmente esgotáveis ou ambientalmente prejudiciais, substituindo-se por recursos ou produtos renováveis e/ou abundantes e ambientalmente inofensivos; redução do volume de resíduos e de poluição, por meio da conservação e reciclagem de energia e recursos; [...] intensificação da pesquisa de tecnologias limpas e que utilizem de modo mais eficiente os recursos para a promoção do desenvolvimento 
urbano, rural e industrial; definição das regras institucionais para uma adequada proteção ambiental, bem como a escolha do conjunto de instrumentos econômicos, legais e administrativos necessários para assegurar o cumprimento das regras. (SACHS, 1993, p. 23).

O diagnóstico do projeto faz alusão a várias das posturas preconizadas por Sachs (1993; 2008; 2003; 2009; 2009b), contudo, percebe-se que, de acordo com o seu entendimento sobre sustentabilidade ambiental, muitas atitudes e posturas ainda se fazem necessárias na atualidade.

Figura 6 - Sistematização dos conceitos atribuídos na Área de Gestão Ambiental das cooperativas tendo por base o desempenho nas subáreas do Diagnóstico

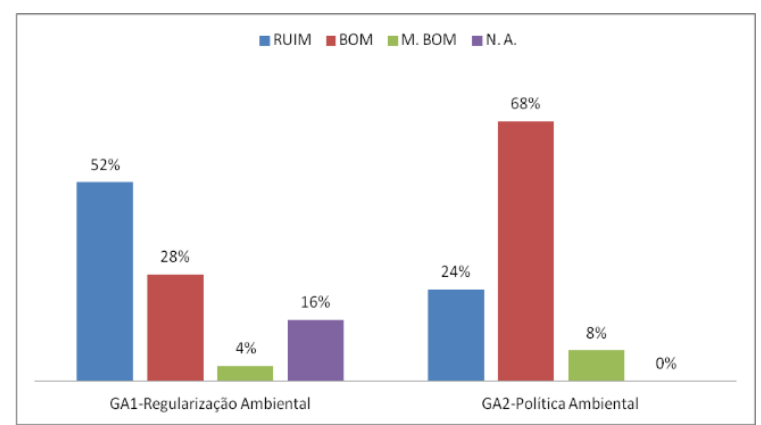

Fonte: Pesquisa, (2015), organizado pelos autores.

A Regularização Ambiental (GA1) faz referência à posse de licença ambiental por parte das agroindústrias, ao plano de manejo das matériasprimas provenientes do extrativismo e às medidas adotadas para resolução de possíveis ou inerentes impactos.

Do universo da pesquisa, em $16 \%$, constatou-se a não aplicabilidade da subárea, e, em 52\%, a constatação foi negativa ("ruim"). Tais dados demonstram a carência de práticas relacionadas à gestão ambiental, visto que a presente subárea está fortemente direcionada a ações concretas.

A implementação de uma Política Ambiental (GA2) consiste nas cooperativas apresentarem preocupação com o meio ambiente, executar projetos

\footnotetext{
${ }^{1}$ São conhecidos os grandes debates sobre a agricultura familiar e o campesinato, contudo, nesse estudo optou-se por utilizar o termo agricultor familiar no lugar do termo camponês, por entender que o primeiro aborda o segmento de forma mais genérica e que o segundo faz referências ao modelo de vida, ao modo de produção e outras características, as quais não foram tratadas e reveladas por meio das análises que se apresentam. $\mathrm{O}$
}

de educação ambiental, adotar estratégias para a diminuição de resíduos, garantir a sustentabilidade da produção, efetuar separação de lixo, entre outros. Tais ações formam o leque de verificação, o qual possibilitou vislumbrar o desempenho das cooperativas estudadas. Em 24\% delas, o desempenho na política ambiental é "ruim". Em 68\%, é "bom", e, em $8 \%$, é "muito bom".

A preocupação com o meio ambiente, abordada no diagnóstico do "Mais Gestão" na subárea "Política Ambiental" constitui um aspecto característico da agricultura familiar, sobretudo aqueles agricultores mais identificados com o campesinato ${ }^{1}$, os quais

[...] atuam como guardiões da paisagem. Quando não são prejudicados por condições de vida insustentáveis, que os forçam ao uso predatório dos recursos naturais, têm em geral uma sensibilidade ecológica maior que a dos grandes empresários agrícolas. (SACHS, 2003, p. 101).

Em resumo, ao se comparar as duas subáreas, a segunda tem mais positividade, de 4 para $8 \%$ no "muito bom", de 28 para $68 \%$ no "bom" e queda no "ruim", de 52 para $24 \%$. Isso pode favorecer a conclusão de que os piores desempenhos se encontram nas ações prática de preservação e gestão ambiental, porém, isso não invalida a preocupação e a vontade das cooperativas em atuar de maneira mais correta.

\section{Considerações finais}

Ao se retomar as informações apresentadas na discussão anterior, contatou-se que o maior gargalo paira sob a área Gestão Organizacional, na qual, em $76 \%$ das cooperativas, a subárea estrutura organizacional encontra-se com desempenho "ruim". Ademais, nota-se que, nessa subárea, nenhuma das cooperativas obteve desempenho "muito bom".

Nota-se ainda que a área Gestão Organizacional, ao lado da área Finanças e Custos não apresentou a conceituação "não se aplica" em nenhuma cooperativa, fato que pressupõe a total

termo aparece nesse momento no texto haja vista que o entendimento do autor citado necessita a sua utilização. Para resolver alguma dúvida sobre as concepções de agricultura familiar e campesinato, sugere-se a leitura do texto de Maria de Nazareth Baudel Wanderley intitulado "Agricultura familiar e campesinato: rupturas e continuidade" publicado na Revista "Estudos Sociedade e Agricultura" em outubro de 2003. 
aplicabilidade das questões abordadas no diagnóstico, referendando a importância dos temas e a necessidade de aprofundamento.

Observa-se que, tendo por base a metodologia do projeto de Ater "Mais Gestão", as cooperativas estudadas caracterizam-se como organizações econômicas da agricultura familiar, as quais aglomeram sujeitos que, na sua maioria, dependem exclusivamente delas para comercializar seus produtos. Contudo, essas organizações encontram-se fragilizadas em diversos aspectos, tais como estrutura organizacional, educação e capacitação, indicadores de recursos humanos, de custos e regularização ambiental. Tal conclusão se fundamenta na análise da matriz de identificação estratégica de cada cooperativa e na análise das subáreas, nas quais o desempenho é "ruim" em mais de $75 \%$ das cooperativas.

Além dos dados apresentados pelas ferramentas utilizadas pelo projeto de ATER, os quais permitiram quantificar a situação das seis áreas do diagnóstico e apontar a Gestão Organizacional como a área mais fragilizada, conclui-se, com base nos autores consultados e tratados neste estudo, que o ponto central para o desenvolvimento das cooperativas da agricultura familiar é a participação das pessoas.

Partindo desse preceito, tem-se um árduo e condicionante desafio para o desenvolvimento do cooperativismo solidário, que é a formação da base cooperada. Essa formação pode ser entendida como uma tarefa a ser desenvolvida em dois momentos distintos, sendo o primeiro diretamente ligado à criação da cooperativa, ou seja, à escolha dos cooperados que irão integrar o quadro social da instituição. $\mathrm{O}$ segundo momento pode ser compreendido como a instauração de um processo formativo, para os casos em que a cooperativa já se encontra em funcionamento e o quadro social tem dificuldade em entender os princípios cooperativos, principalmente os que se referem à participação ativa na sociedade.

Muitos dos empreendimentos cooperativos são compostos por pessoas que não são adeptas ao cooperativismo e tampouco à economia solidária. A cultura do individualismo ainda impera nesses empreendimentos, os quais se caracterizam como uma plataforma de acesso a políticas públicas e mercados que priorizam o setor, tal qual o PAA e o PNAE.
Posto isso, conclui-se que um dos desafios a ser superado pelo cooperativismo da agricultura familiar no estado do Paraná é a capacitação dos seus quadros em diversos temas, mas iniciando pelos estruturantes, como associativismo, cooperação, solidariedade, desenvolvimento, para que depois possam ser abordados temas mais técnicos ligados à área produtiva ou comercial.

Motivar as pessoas para a participação, para a autogestão, é um grande desafio para as cooperativas da agricultura familiar tratadas nesse estudo, sendo também o desafio de grande parte do cooperativismo que trabalha sob os preceitos da economia solidária. A autogestão é um modelo tido como pertinente para estes empreendimentos, porém, faz-se necessário mobilizar os cooperados para atuarem nesses moldes.

Ao constatar que a gestão organizacional é a subárea que possui maiores fragilidades, conclui-se que o investimento mais assertivo para as cooperativas é nas pessoas, no quadro social, na participação dos cooperados, na valorização e prática cotidiana da democracia.

Ademais, a qualificação das pessoas para atuar na gestão é um ponto chave para que estes empreendimentos logrem êxito. Antes mesmo de os cooperados estarem aptos a exercer a gestão financeira, a gestão comercial, a gestão da comercialização, a gestão ambiental e a gestão industrial, precisam ser adeptos e partidários da autogestão, da participação e da cooperação.

\section{Referências}

AVILA, Mário Lúcio et al. Nova Lei de Ater e inovações em políticas públicas: o caso do programa "Mais Gestão". In: Encontro Nacional da ANPPAS, 7., 2015, Brasília. Anais [...]. Brasília, 2015.

ARROYO, João Claudio; SCHUCH, Flávio Camargo. Economia popular e solidária: a alavanca para um desenvolvimento sustentável e solidário. Editora Fundação Perseu Abramo, 2006.

BATALHA, Mário Otávio; BUAINAIN, Antônio Márcio; SOUZA FILHO, Hildo Meirelles de. Tecnologia de gestão e agricultura familiar. In: BATALHA, Mário Otávio; SOUZA FILHO, Hildo Meirelles de (org). Gestão Integrada da 
Agricultura Familiar. São Carlos. EdUFSCar, 2005.

BIALOSKORSKI NETO, Sigismundo. Aspectos econômicos das cooperativas. Belo Horizonte: Mandamentos. 2006.

COSTA, Bianca Aparecida Lima; AMORIM JUNIOR, Paulo Cesar Gomes; SILVA, Marcio Gomes da. As cooperativas de agricultura familiar e o mercado de compras governamentais em Minas Gerais. Rev. Econ. Sociol. Rural, Brasília, v. 53, n. 1, p. 109-126, 2015.

CRUZIO, Helnon de Oliveira. Marketing social e ético nas Cooperativas. Rio de Janeiro: FGV, 2003.

DATER. Departamento de Assistência Técnica e Extensão Rural. Chamada pública para seleção de entidade de assistência técnica e extensão rural para qualificação da gestão de empreendimentos coletivos da agricultura familiar visando seu fortalecimento e inserção nos mercados institucionais e privados. Chamada Pública SAF/ATER nº6/2012. Brasília, 2012b.

DIAS, Emerson de Paulo.Conceitos de Gestão e Administração: Uma Revisão Crítica. Revista Eletrônica de Administração, FACEF, v. 1, n. 1, jul./dez., 2002.

DUARTE, Laura Maria Goulart; WEHRMANN, Magda Eva S. de F. Histórico do cooperativismo agrícola no Brasil e perspectivas para a agricultura familiar. Associativismo, Cooperativismo e Economia Solidária no Meio Rural, p. 13, 2006.

FRANTZ, Walter. Associativismo, Cooperativismo Economia Solidária. Ijuí: Editora Unijuí, 2012.

GERHARDT, Tatiana Engel; SILVEIRA, Denise Tolfo. Método de pesquisa. Porto Alegre: Editora da UFRGS, 2009

GIL, Antonio Carlos. Métodos e técnicas de pesquisa social. São Paulo: Atlas, 2008.
GOODE, William Josiah; HATT, Paul K. Métodos em pesquisa social. 4. ed. São Paulo: Nacional, 1972. $488 \mathrm{p}$.

GUTIERREZ, Gustavo Luiz. Autogestão de empresas: considerações a respeito de um modelo possível. Revista de Administração de Empresas, São Paulo, v. 28, n. 2, p. 7-19, Jun., 1988.

IGNÁCIO, Olímpia Maria de Carvalho. Gestão estratégica aplicada ao cooperativismo solidário: uma alternativa de fortalecimento para os agricultores familiares. 2008, $166 \mathrm{f}$. Dissertação (Mestrado) - Universidade Federal de Goiás. Escola de Agronomia e Engenharia de Alimentos, Programa de Pós-Graduação em Agronegócio, 2008.

LAUSCHNER, Roque. Cooperativismo e agricultura familiar. Publicado em outubro de 1994. Mimeo, p.7.

LAKATOS, Eva Maria; MARCONI, Maria de Andrade. Fundamentos da metodologia científica. São Paulo: Atlas, 2003.

LIMA FILHO, Sebastião Correia de. Capital social e desenvolvimento sustentável: a experiência de Campo do Brito (SE). Revista Econômica do Nordeste, v. 42, n. 1, p. 139-163, 2016.

LOPES, Kátia Lene de Araujo; MATOS, Fátima Regina Ney; MACHADO, Diego de Queiroz. Cooperativismo como Alternativa para o Desenvolvimento Sustentável Local: Estudo de Caso nas Cooperativas do Perímetro Irrigado de Morada Nova/CE. Sistemas \& Gestão, v. 10, n. 2, p. 214-224, 2015.

MARTINEZ-ALIER, Joan. Idiomas de Valoração. Boletim da Sociedade Brasileira de Economia Ecológica, n. 19, 2008.

MAXIMIANO, Antonio Cesar Amaru. Introdução à Administração. 5. ed. rev. ampl. São Paulo: Atlas, 2000. 546 p. 
MENDONÇA, Sonia Regina de. A hegemonia do agronegócio no Brasil: uma construção em disputa. Espaço Plural, v. 12, n. 24, 2011.

MILKOVICH, George T.; BOUDREAU, John W. Administração de recursos humanos. 1. ed., 4. tir. São Paulo: Atlas, 2000.

ORLICKAS, Elizenda. Consultoria interna de recursos humanos: conceitos, casos, estratégia. São Paulo: Makron Books, 1998.

PIRES, Maria Luiza Lins e Silva. et al. Cenário e tendência do Cooperativismo Brasileiro. Recife: Bagaço, 2004.

SACHS, Ignacy. Caminhos para o desenvolvimento sustentável. Rio de Janeiro: Garamond, 2009.

SACHS, Ignacy. Desenvolvimento includente, sustentável e sustentado. Rio de Janeiro: Garamond, 2008.

SACHS, Ignacy. Estratégias de transição para o século XXI: desenvolvimento e meio ambiente. São Paulo: Studio Nobel/Fundap, 1993.

SACHS, Ignacy. Gestão social para desenvolvimento sustentável e democrático dos territórios. In: BACELAR, Tânia (Org). Gestão Social Dos Territórios. Brasília: IICA, 2009b. (Série Desenvolvimento Rural Sustentável, v. 10).

SACHS, Ignacy. Inclusão social pelo trabalho: desenvolvimento humano, trabalho decente e o futuro dos empreendedores de pequeno porte. Rio de Janeiro: Garamond, 2003.

SCHNEIDER, José Odelso. A doutrina do cooperativismo: análise do alcance, do sentido e da atualidade dos seus valores, princípios e normas nos tempos atuais. Cadernos Gestão Social, v. 3, n. 2, p. 251-273, 2012.

SCHNEIDER, José Odelso. Cooperativismo e desenvolvimento sustentável. Otra Economía, v. 9, n. 16, p. 94-104, 2015.
SEN, Amartya. Desenvolvimento como liberdade. São Paulo: Companhia das Letras, 2013.

SILVA-ARIOLI, Inea Giovana et al. Cooperativismo e Economia Solidária: a constituição de uma Cooperativa de Catadores de Resíduos Sólidos em São Joaquim (SC). Otra Economía, v. 10, n. 19, p. 164-175, 2016.

SILVA, Christian Luiz da; LOURENÇO, Marcus Santos; SALANEK FILHO, Pedro. Capital social e cooperativismo no processo de desenvolvimento sustentável local: teorias e aplicações ao caso da cooperativa Bom JesusLapa/PR. In: Encontro Nacional de PósGraduação em Administração-ENANPAD, 30., Salvador. Anais [...]. Salvador: ENANPAD, 2006.

SINGER, Paul. Desenvolvimento capitalista e desenvolvimento solidário. Estudos Avançados, v. 18, n. 51, São Paulo, mai./ago., 2004.

SINGER, Paul. Economia Solidária - Entrevista com Paul Singer. Estudos Avançados, v. 22, n. 62, São Paulo, jan./abr., 2008.

SINGER, Paul. Introdução a Economia Solidária. 5. ed. São Paulo: Editora Fundação Perceu Abramo, 2013

SIQUEIRA, Haloysio Miguel de et al. Comercialização solidária da produção familiar de alimentos em Alegre-ES. Revista Extensão Rural, Santa Maria, v. 21, n. 3, set./dez., 2013.

ZYLBERSZTAJN, Decio. Administração de sistemas de base agrícola: análise de fatores críticos. Revista de Administração, São Paulo, v. 48, n. 2, jun., 2013. 
